\title{
Obstetric hysterectomy: a surgical emergency 3 years review in a tertiary care centre
}

\author{
Shanti Sah*, Shipra Gupta \\ Department of Obstetrics and Gynecology, SRMSIMS, Bareilly, Uttar Pradesh, India
}

Received: 14 June 2021

Accepted: 09 July 2021

*Correspondence:

Dr. Shanti Sah,

E-mail: shantisahmsog@gmail.com

Copyright: () the author(s), publisher and licensee Medip Academy. This is an open-access article distributed under the terms of the Creative Commons Attribution Non-Commercial License, which permits unrestricted non-commercial use, distribution, and reproduction in any medium, provided the original work is properly cited.

\section{ABSTRACT}

Background: Obstetric haemorrhage is a life threatening complication associated with increased maternal morbidity and mortality. Its incidence is $0.2-4$ per 1000 deliveries in developed countries and much higher in developing countries. The main cause still remains rupture uterus, postpartum hemorrhage (PPH) and placenta accreta spectrum (PAS).

Methods: A retrospective analysis of obstetric hysterectomies performed over a period of 3 years from July 2017 to June 2020 was done. Incidence, risk factors, indication, outcome and complications of obstetric hysterectomies were evaluated.

Results: A total 72 cases of obstetric hysterectomy were performed over 3 years period. Out of 72 cases, $33 \%, 28 \%$ and $14 \%$ cases were of peripartum hysterectomy done due to rupture uterus, PAS and PPH respectively. There was an increase in the incidence of PAS compared to previous years. There was no observed difference among patients undergoing total or subtotal hysterectomies. No difference as regard to duration of surgery, pre-operative or postoperative hemoglobin, IV fluid and blood product transfusion was noted among elective and emergency procedures. Statistically significant blood loss was observed in emergency hysterectomy compared to elective hysterectomy with $\mathrm{p}$ value of 0.004. An average need of transfusions was double in case of peripartum hysterectomy done for PPH compared to rupture uterus or adherent placenta. Bladder injury, burst abdomen and resuturing were three important morbidities. Maternal mortality was $2.8 \%$ in our study population.

Conclusions: Emergency obstetric hysterectomy still remains a live saving procedure in case of catastrophic intractable hemorrhage and rupture uterus. Proper antenatal supervision, identification of risk factors and timely referral can reduce the incidence of associated morbidity and mortality.

Keywords: Obstetric hysterectomy, Peripartum hysterectomy, Rupture uterus, PAS, PPH, Total hysterectomy, Subtotal hysterectomy, Elective, Emergency

\section{INTRODUCTION}

Any physical or mental illness directly related to pregnancy is referred as maternal morbidity. ${ }^{1}$ One of the important causes being obstetric hysterectomy which is performed on gravid uterus during pregnancy or in puerperium. Peripartum hysterectomy done following caesarean section or vaginal delivery or till end of puerperium due to any indication associated with pregnancy. ${ }^{2}$ Besides bringing an abrupt end to women's reproductive potential it also results in various complications including need for multiple blood transfusions, ICU admission and can be considered as near-miss cases. The main indication of peripartum hysterectomies are rupture uterus, adherent placenta or PPH. However, drug treatment and other modalities has led to decrease in its occurrence but when life threatening haemorrhage occurs surgical approach usually helps. 


\section{METHODS}

The present study was conducted in department of obstetrics and gynaecology, SRMS IMS, Bareilly, a referral centre. All patients who underwent hysterectomy due to pregnancy related complications were included over a period of 3 years (July 2017 to June 2020).

Records of all women were obtained from medical record department. Each case file was analysed for detail regarding age, parity, gestational age, previous surgical interventions, clinical characteristics, operative and intraoperative findings, duration of surgery and post-operative events. The data were compared based on elective and emergency procedure. A comparison between type of obstetric hysterectomy and changes in indication over 3 years period was also observed. Data was analysed by $t$ test.

\section{RESULTS}

A total of 8035 deliveries (3709 vaginal and 4326 caesarean) occurred in a 3 years period (July 2017 to June 2020). Total of 72 obstetric hysterectomies $(0.896 \%)$ was performed during this period. Out of 72 cases, 15 cases were elective surgeries and 57 had emergency surgeries.

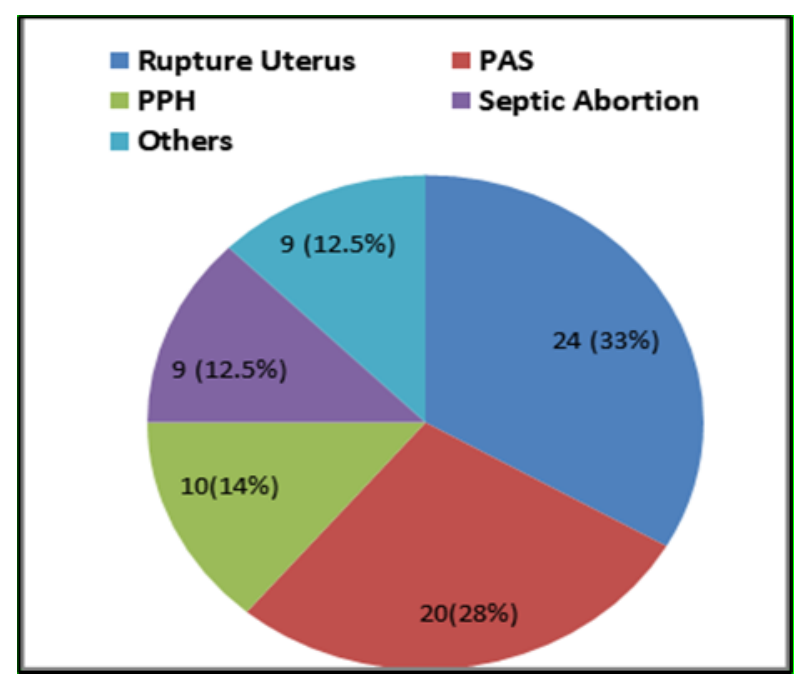

Figure 1: Indications of hysterectomy: total incidence.

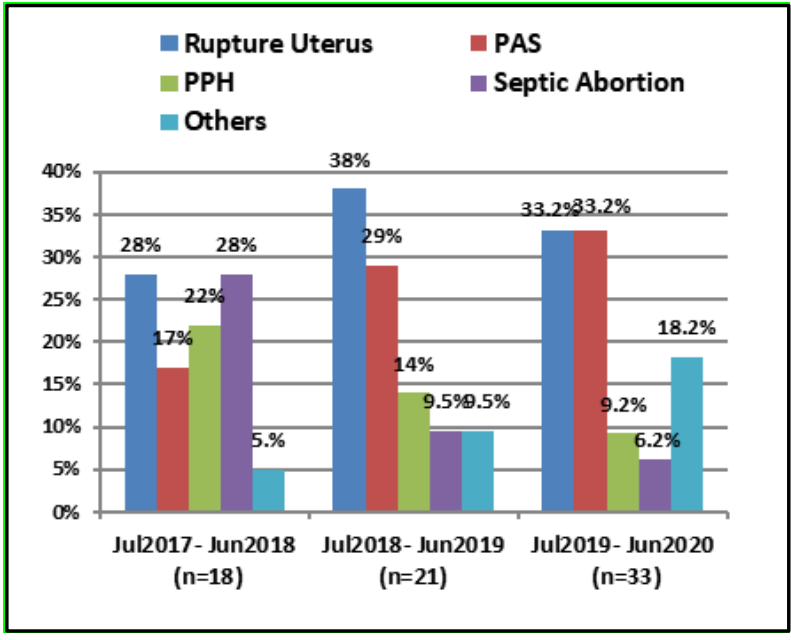

Figure 2: Changing trends over a period of 3 years: Year-wise incidence.

Mean age was $29.402 \pm 5.5$ years, maximum patient were of gravid 3 or more with gestational age $\geq 37$ weeks.

Other causes of obstetric hysterectomies includes post LSCS hemo/pyoperitoneum, cornual/cervical/caesarean scar pregnancy and invasive mole. The incidence of PAS has increase from $17 \%$ to $33.2 \%$ in two years duration.

Mean PRBC and FFP transfused was twice in case of PPH compared to other causes. Overall requirement of PRBC in case of rupture uterus, PAS or septic abortion are comparable.

Out of 72 hysterectomies, 43 underwent total hysterectomy and rest 29 cases underwent subtotal hysterectomy. There was insignificant difference in $p$ value with regard to duration of surgery and blood loss in both groups.

Out of 72 cases, post-operative complications occurred in 25 cases $(34.7 \%)$. ICU admission was required in 18 cases (25\%) out of which 17 cases were admitted for 1 day and only 1 case required intensive care for 2 days. Intraoperative vasopressor was required in 14 cases (19.4\%), out of which only 1 case required 2 vasopressor support (noradrenaline and dopamine) while in rest all cases BP was maintained on single vasopressor (noradrenaline).

Table 1: Maternal characteristics of cases undergoing elective versus emergency hysterectomies.

\begin{tabular}{|llll|}
\hline Maternal characteristics & & Elective $(\mathbf{N}=15)$ & Emergency $(\mathbf{N}=\mathbf{5 7})$ \\
\hline \multirow{3}{*}{ Age (in years) } & & $31.8 \pm 5.32$ & $28.77 \pm 5.36$ \\
\hline \multirow{3}{*}{ Gravida status } & Primi & 2 & 4 \\
\cline { 2 - 4 } & 2nd gravida & 1 & 13 \\
\cline { 2 - 4 } Gestational age (in weeks) & $\geq 3$ rd gravida & 12 & 40 \\
\cline { 2 - 4 } & $<28$ & 6 & 9 \\
\cline { 2 - 4 } & $28-34$ & 3 & 11 \\
\cline { 2 - 4 } & $34-37$ & 4 & 28 \\
\hline
\end{tabular}


Table 2: Anesthesia and peri-operative management of elective versus emergency hysterectomies.

\begin{tabular}{|c|c|c|c|c|}
\hline \multicolumn{2}{|l|}{ Operative details } & Elective $(\mathbf{N}=\mathbf{1 5})$ & Emergency $(\mathrm{N}=57)$ & P value \\
\hline \multirow{2}{*}{ Anaesthesia } & Spinal (S. A.) & 14 & 28 & \multirow[b]{2}{*}{-} \\
\hline & General (G. A.) & 1 & 29 & \\
\hline \multirow{2}{*}{ Initial BP (in mmHg) } & Systolic & $113.73 \pm 12.09$ & $105.54 \pm 20.88$ & 0.057 \\
\hline & Diastolic & $72.67 \pm 9.61$ & $68.24 \pm 13.38$ & 0.157 \\
\hline \multicolumn{2}{|c|}{ Pre-operative hemoglobin (in g/dl) } & $8.77 \pm 2.31$ & $8.38 \pm 2.61$ & 0.577 \\
\hline \multirow{2}{*}{ IV fluid transfused } & Crystalloid & (39) $2.6 \pm 0.91$ & (127) $2.23 \pm 0.98$ & 0.181 \\
\hline & Colloid & (13) $0.87 \pm 0.74$ & (50) $0.88 \pm 0.59$ & 0.962 \\
\hline \multirow{4}{*}{ Blood product transfused } & PRBC & (31) $2.07 \pm 1.03$ & (161) $2.82 \pm 2.54$ & 0.086 \\
\hline & FFP & (36) $2.4 \pm 1.72$ & (219) $3.84 \pm 4.42$ & 0.055 \\
\hline & Platelet & (14) $0.93 \pm 2.25$ & (70) $1.23 \pm 2.59$ & 0.66 \\
\hline & Total & (81) $1.8 \pm 1.82$ & $(450) 2.63 \pm 3.46$ & 0.213 \\
\hline \multicolumn{2}{|l|}{ Estimated blood loss (in ml) } & $1690 \pm 545.17$ & $2186.84 \pm 469.10$ & 0.004 \\
\hline \multicolumn{2}{|l|}{ Duration of surgery (in hrs) } & $2.36 \pm 0.84$ & $2.03 \pm 0.62$ & 0.172 \\
\hline \multicolumn{2}{|c|}{ Post transfusion hemoglobin (in g/dl) } & $7.91 \pm 1.16$ & $7.78 \pm 1.58$ & 0.725 \\
\hline
\end{tabular}

3 elective and 2 emergency cases where $\mathrm{S}$. A. was given were converted to G. A.

Table 3: Requirement of blood products in association with indications of hysterectomies.

\begin{tabular}{|llllllll|}
\hline & $\begin{array}{l}\text { No. of } \\
\text { cases (out } \\
\text { of 72) }\end{array}$ & $\begin{array}{l}\text { PRBC } \\
\text { Total } \\
\text { units } \\
\text { transfused }\end{array}$ & $\begin{array}{l}\text { Mean } \\
\text { transfusion }\end{array}$ & $\begin{array}{l}\text { Total } \\
\text { units } \\
\text { transfused }\end{array}$ & $\begin{array}{l}\text { Mean } \\
\text { transfusion }\end{array}$ & $\begin{array}{l}\text { Total units } \\
\text { transfused }\end{array}$ & $\begin{array}{l}\text { Mean } \\
\text { transfusion }\end{array}$ \\
\hline Rupture uterus & 24 & 60 & $2.5 \pm 1.62$ & 76 & $3.16 \pm 5.14$ & 25 & $1.04 \pm 2.19$ \\
\hline PAS & 20 & 45 & $2.25 \pm 2.3$ & 66 & $3.3 \pm 4.1$ & 19 & $0.95 \pm 2.5$ \\
\hline PPH & 10 & 48 & $4.8 \pm 2.5$ & 54 & $5.4 \pm 4.5$ & 25 & $2.5 \pm 2.6$ \\
\hline Septic abortion & 9 & 23 & $2.56 \pm 2.5$ & 25 & $2.78 \pm 4.4$ & 4 & $0.44 \pm 2.5$ \\
\hline Others & 9 & 16 & $1.78 \pm 1.4$ & 34 & $3.78 \pm 4.6$ & 11 & $1.22 \pm 1.8$ \\
\hline
\end{tabular}

Table 4: Relation of type of hysterectomy with peri-operative management.

\begin{tabular}{|llll|}
\hline Operative details & Total hysterectomy $(\mathbf{N}=43)$ & Subtotal hysterectomy $(\mathbf{N}=\mathbf{2 9})$ & P value \\
\hline Estimated blood loss (in ml) & $2052.32 \pm 566.31$ & $2129.31 \pm 546.0$ & 0.565 \\
\hline Duration of surgery (in hrs) & $2.07 \pm 0.65$ & $2.14 \pm 0.7$ & 0.67 \\
\hline
\end{tabular}

Table 5: Intra and post-operative complications.

\begin{tabular}{|ll|}
\hline Complications & No. of patients $(\boldsymbol{\%})$ \\
\hline Bladder rupture & $6(8.3)$ \\
\hline Burst abdomen & $4(5.6)$ \\
\hline Re-suturing & $4(5.6)$ \\
\hline Re-exploration & $3(4.2)$ \\
\hline Dialysis & $2(2.8)$ \\
\hline VVF & $1(1.4)$ \\
\hline Febrile illness & $1(1.4)$ \\
\hline Urinary retention & $1(1.4)$ \\
\hline Intestinal obstruction & $1(1.4)$ \\
\hline Mortality & $2(2.8)$ \\
\hline ICU admission & $18(25)$ \\
\hline Need of vasopressor & $14(19.4)$ \\
\hline
\end{tabular}


Table 6: Association and grade of PAS.

\begin{tabular}{|lll|}
\hline \multirow{3}{*}{ Findings } & & No. of cases (\%) \\
& Scarred uterus (post C. S.) & $14(70)$ \\
\cline { 2 - 3 } & h/o D and C & $3(15)$ \\
\cline { 2 - 3 } & Unscarred uterus & $3(15)$ \\
\hline \multirow{3}{*}{ Grade } & Percreta & $4(20)$ \\
\hline & Accreta & $11(55)$ \\
\hline Increta & $5(25)$ \\
\hline
\end{tabular}

Table 7: Cause of shock.

\begin{tabular}{|l|c|}
\hline Causes of shock & Incidence (\%) \\
\hline Rupture uterus & $7(9.7)$ \\
\hline Uterine perforation (septic abortion) & $3(4.2)$ \\
\hline Atonic PPH & $3(4.2)$ \\
\hline Atonic+traumatic PPH & $2(2.8)$ \\
\hline Post LSCS haemoperitoneum & $2(2.8)$ \\
\hline Rupture cornual pregnancy & $1(1.3)$ \\
\hline Total & $18(25)$ \\
\hline
\end{tabular}

\section{DISCUSSION}

In our review study, a total of 72 cases underwent obstetric hysterectomy over a period of 3 years. Out of which 57 cases $(79.2 \%)$ were of peripartum hysterectomy which has been done either during caesarean section or following vaginal delivery or immediately post-partum rest 15 cases $(20.8 \%)$ were due to ectopic pregnancy (cornual/cervical/caesarean scar pregnancy) or following $1 \mathrm{st} / 2$ nd trimester septic abortion, 1 case underwent hysterectomy due to invasive mole. Out of 72 surgeries, 15 cases $(20.8 \%)$ were of elective surgeries where peripartum hysterectomy was anticipated rest 57 cases $(79.2 \%)$ were taken for emergency procedure for life threatening haemorrhage. The mean age among our study population was $29.40 \pm 5.5$ years whereas mean age of elective cases was $31.8 \pm 5.32$ years. Maximum cases were gravida 3 or more. Majority of cases had gestational age $\geq 34$ weeks (late preterm/term pregnancy).

There was a change in trend regarding the indication for obstetric hysterectomy over past 3 years (Figure 2). Comparing the major indications peripartum hysterectomy done for rupture uterus had decreased compared to previous years, however the incidence was yet high mostly due to fear of repeat section in institutional delivery and conduction of TOLAC by untrained health care providers. The associated cause of rupture uterus was history of previous caesarean section observed in 14 cases $(58.3 \%)$. 2 cases $(8.3 \%)$ had a history of previous rupture uterus repair and 1 case $(4.2 \%)$ had h/o previous cornual excision and repair. Overzealous use of oxytocin was seen in 4 cases $(16.6 \%)$ while 1 case $(4.2 \%)$ each of version and difficult vaginal delivery lead to rupture uterus. Our findings were in accordance with a review literature on incidence of rupture uterus in developing countries where incidence with prior caesarean section or uterine scar who had rupture was upto $64 \% .^{3}$ However, magnitude of uterine rupture in our setting was $0.29 \%$ (24 cases out of 8035 deliveries) which was discordant to study conducted by Astatikie et al wherein magnitude of rupture uterus was $2.44 \% .^{4}$

The incidence of peripartum hysterectomy due to PAS has increased over past years due to increase in caesarean section rate. Overall incidence of surgery due to rupture uterus was $33 \%$ followed by PAS, $28 \%$ (Figure 1). PAS or pathologically adherence of placenta mostly occurs due to increase in caesarean section rate or history of dilatation and curettage. Scarred uterus is associated with $85 \%$ cases of PAS in our study (Table 6) while risk of emergency peripartum hysterectomy with abnormal placentation reported by Macchado et al was $45-73.3 \%$ and $44 \%$ according to Rawashdeh et al. ${ }^{5,6}$ In concordance to our findings, Dilpreet et al in their study concluded $88.9 \%$ cases of PAS associated with scarred uterus and Smita et al found association of scarred uterus with all cases of PAS. ${ }^{7,8}$

Out of 4 cases, 3 cases of placenta percreta was observed with history of previous 2 LSCS whereas PAS and increta was seen more frequently with history of previous 1 LSCS. The reason being defect of endometrial-myometrial interface leading to failure of normal decidualization in area of uterine scar allowing abnormally deep placental anchoring villi and trophoblast infiltration. ${ }^{9}$

Incidence of $\mathrm{PPH}$ has decreased due to effective uterotonics and other intervention as balloon tamponade and compression sutures. A meta-analysis found that all newer techniques are equally effective in controlling haemorhage with a success rate of $84.0 \%$ for balloon 
tamponade, $90.7 \%$ for arterial embolization, $91.7 \%$ for compression sutures and $84.6 \%$ for pelvic devascuralization (including uterine and internal iliac artery ligation). ${ }^{10}$ Uterine artery embolization (UAE) is an effective approach in case with antenatal anticipation of adherent placenta or atonic PPH limiting blood transfusion and can save life but has a limited role in emergency cases and resource limited condition. The risk to infant from fluoroscopy dose was considered negligible ( $<50 \mathrm{mGy})$ however major complication of UAE includes transient fever, pelvic pain, transient foot ischemia, transient menelipsis and abscess. ${ }^{11,12}$ In our study, PPH was commonly observed in multigravida with $\geq 3$ parity, only 2 cases of primigravida had PPH. Emergency peripartum hysterectomy for atonic PPH was seen in 10 cases (14\%) in our study (Figure 1) out of which 2 cases had associated traumatic PPH whereas in study conducted by Anshuja et al $45.87 \%$ cases had atonic PPH leading to emergency hysterectomies. ${ }^{13}$

Emergency obstetric hysterectomy in our study was also done for post-operative and post-abortal complication. Septic abortion leading to uterine perforation and adjoining organ injury with life threatening haemorrhage was associated in $12.5 \%$ cases while early pregnancy complications as cornual/cervical/caesarean scar pregnancy and molar pregnancy associated with $8.3 \%$ cases (6 out of 72) and postoperative complication requiring peripartum hysterectomy occurred in $4.1 \%$ cases (3 out of 72). Similarly, Dilpreet et al also observed 12.1\% cases of septic abortion underwent emergency obstetric hysterectomy and $2.4 \%$ of emergency obstetric hysterectomy occurred in invasive mole while Smita et al observed ectopic pregnancy in $16.6 \%$ and molar pregnancy in $5.5 \%$ cases of emergency obstetric hysterectomy. ${ }^{7,8}$

Pre-operative and intra-operative parameters were compared in patients undergoing obsteritc hysterectomy among two groups (elective and emergency surgeries) (Table 2). Most cases of elective surgery were done under S. A. whereas $49 \%$ cases of emergency surgery were done under S. A. The mean systolic BP was $105.54 \pm 20.88 \mathrm{~mm}$ $\mathrm{Hg}$ for emergency surgery which was statistically significant compared with elective cases $(\mathrm{p}=0.057)$. Most cases were stable at admission. Out of 72 cases only 18 cases presented in state of shock requiring resuscitation (Table 7).

There was no statistically significant difference among the haemoglobin values observed pre and postoperatively following transfusion, however, the mean haemoglobin in emergency surgery was $8.38 \pm 2.61 \mathrm{~g} / \mathrm{dl}$ and $7.78 \pm 1.58 \mathrm{~g} / \mathrm{dl}$ pre-operatively and post tansfusion post-operatively respectively (Table 2 ). There was a statistically significant amount of blood loss with $\mathrm{p}$ value 0.004 between elective and emergency surgeries. A mean of 2.62 \pm 3.46 units of blood product were required in emergency surgeries compared to $1.8 \pm 1.82$ units in elective procedure. IV fluids required in both cases were comparable. Our findings were different to observations of Bharti et al where estimated blood loss was $2.6 \pm 1.2$ and $2.8 \pm 1.6 \mathrm{ltr}$ respectively for elective and emergency surgeries, however in accordance to our study there was an insignificant $p$ value in both groups regarding duration of surgery, IV fluids, blood transfusion and postoperative haemoglobin. ${ }^{14}$

An average of 6.7 and 6.5 units of blood products were required in case of emergency peripartum hysterectomy done for rupture uterus and PAS whereas 12.7 units blood products were needed in case of PPH (Table 3). Mean PRBC and FFP required in case of $\mathrm{PPH}$ was twice compared to rupture uterus and PAS. One patient had 26 units FFP transfused due to PPH with DIC. Mean intraopertaive blood transfusion was $4.1 \pm 2.4$ units according to Bharti et al. ${ }^{14}$

Out of 72 obstetric hysterectomy subtotal hysterectomy done in 29 cases $(40.3 \%)$ while in 43 cases $(59.7 \%)$ total hysterectomy was performed (Table 4). There was no observed statistical difference with regard to mean duration of surgery and estimated blood loss in our study. Rawashdeh et al also had similar observations between total and subtotal hysterectomy with no significant difference in term of duration of surgery, estimated blood loss and blood transfusion, need of vasopressors and ICU admissions or complications. ${ }^{6}$

Out of 72 cases, 25 cases (34.7\%) had post-operative complication (Table 5). Most common complication was bladder injury occurring in $8.3 \%$ cases ( 6 out of 72 ) either associated with uterine rupture or due to placental invasion. Burst abdomen and wound dehiscence occurred in $5.6 \%$ cases each while reexploration was required in $2.8 \%$ cases. Indifferent to our finding Qatawneh et al observed $21.6 \%$ cases of bladder injury, $5.4 \%$ cases of wound infection and $4.05 \%$ cases requiring reexploration, Bharti et al recorded $20 \%$ cases of bladder injury and $2.5 \%$ cases each requiring resuturing and reexploration. ${ }^{14,15}$ Smita et al observed $27.11 \%$ cases with bladder injury and $11.11 \%$ cases of wound infection. ${ }^{8}$ Mortality incidence in our study was $2.8 \%$. In contrast to our findings, mortality incidence was $10 \%, 16.66 \%$ and $17.9 \%$ according to study conducted by Bharti et al, Smita et al and Chawla et al respectively. ${ }^{2,8,14}$ Rawashdeh et al in their study observed only $1.69 \%$ mortality rate. $^{6}$

\section{CONCLUSION}

We concluded that the incidence of obstetric hysterectomies had increased in our institute. The incidence related to adherent placenta is gradually increasing, this is because of rising caesarean section rate. However early detection by antenatal screening, proper counselling and early referral can decrease the incidence of maternal morbidity and mortality because of availability of other intervention modalities and proper intranatal supervision. 


\section{ACKNOWLEDGMENTS}

Author would like to thank medical record department to assess the patients record.

Funding: No funding sources

Conflict of interest: None declared

Ethical approval: The study was approved by the Institutional Ethics Committee

\section{REFERENCES}

1. Koblinsay M, Chaudhary ME, Moran A, Ronsmans C. Maternal morbidity and disability and their consequences: neglected agenda in maternal health. J Health Popul Nutr. 2012;30(2):124-30.

2. Chawla J, Arora D, Paul M, Ajmani SN. Emergency obstetric hysterectomy:a retrospective study from a teaching hospital in North India over 8 years Oman Med J. 2015;30(3):181-6.

3. Berhe Y, Wall LL. Uterine rupture in resource-poor countries. Obstet Gynecol Surv. 2014;69,694-707.

4. Astatikie G, Limenih MA, Kebede M. Maternal and fetal outcome of uterine rupture and factors associated with maternal death secondary to uterine rupture. BMC Pregnancy Childbirth. 2017;17(1):117.

5. Machado LSM. Emergency peripartum hysterectomy: incidence, indication, risk factors and outcome. N Am J Med Sci. 2011;3(8):358-61.

6. Rawashdeh H, Obeidat R, Masaadeh L. Emergency peripartum hysterectomy in a tertiary teaching hospital in Northern Jordan: a 15 year review: Gynecol Surg. 2021;18:1.

7. Dilpreet KP, Sehgal A, Aggarwal N. Frequency, indication and maternal outcome in obstetric hysterectomy in a tertiary care centre in India. JK Sci. 2015;17(1):8-12.
8. Smita SB, Verma A, Sharma M. Emergency obstetric hysterectomy, risk factor, indication and outcome: a retrospective two year study. Int J Cur Res Rev. 2017;9(17):41-4.

9. Obstetric care consensus No 7: Placenta Accreta Spectrum. American College of Obstetricians and Gynecologists. Obstet Gynecol. 2018;132(6):e259e275.

10. Doumauchtsis SK, Papegeorghiou AT, Arulkumaran S. Systemic review of conservative management of postpartum hemorrhage: what to do when medical treatment fails. Obstet Gynecol Surv. 2007;62(8):5407.

11. Natu N, Patel K, Chandwaskar N, Chauhan A, Arora A, Kumar R. Management of placenta accreta by uterine artery embolization: a case report. Tanta Med J. 2021;43(1):36-8.

12. Qun L, Yang ZQ, Mohammed W, Feng YL, Shi HB, Zhou X. Prophylactic uterine artery embolization assisted caesarean section for the prevention of intrapartum hemorrhage in high risk patients. Cardiovasc Intervent Radiol. 2014;37(6);1458-63.

13. Anshuja S, Mundhra R, Phogat L, Mehta S, Rajaram S. Emergency peripartum hysterectomy: indications and outcome in a tertiary care setting. JCDR. 2017;11(3):1-3.

14. Bharti S, Sikka P, Jain V, Jain K, Bagga R, Suri V. Peripartum hysterectomy in a tertiary care hospital: epidemiology and outcomes. J Anesthesiol Clin Pharmacol. 2017;33:324-8.

15. Qatawneh A, Fram KM, Thikerallah F, Mhidat N, Fram FK, Fram RK, et al. Emergency peripartum hysterectomy at Jordan university hospital: a teaching hospital experience. Menopause Rev. 2020;19(2):6671.

Cite this article as: Sah S, Gupta S. Obstetric hysterectomy: a surgical emergency 3 years review in a tertiary care centre. Int J Reprod Contracept Obstet Gynecol 2021;10:2999-3004. 